\title{
Developing Effective Global Leadership
}

Maryam Hassanzadeh

H/p:011 23848667; maryam.hassanzadeh@outlook.com

Abu Daud Silong, PhD

H/p:017 3828747; abudaud.silong@gmail.com

Azizan Asmuni, PhD

Nor Wahiza Abd Wahat, PhD

Department of Professional Development and Continuing Education, Faculty of Educational Studies

Universiti Putra Malaysia

Doi:10.5901/jesr.2015.v5n3p15

\section{Abstract}

The main purpose of this paper is to answer the question: how can we develop an effective global leadership? It is based on a research conducted using a qualitative method involving in-depth interviews of selected participants who have the experiences in the field of leadership in a selected university. The interviews were then transcribed verbatim, coded and analyzed. Going to the future Malaysia will intensify its efforts to become a developed nation by 2020. Transforming the nation from middle to higher income will require leaders who are robust enough to face diverse and complex environment. With rapid globalization, there is recognition for more global leadership development. Global leadership is defined as a leader who operates on a global stage with a open mindset in a complex and diverse environment. Currently, there was a shortage of global leaders. Organizations accept this situation and need to improve in developing global leaders. As organizations' operations expand across the world, the demand for global leaders is increasing. However, many organizations are struggling with a critical shortage of effective global leaders. They need the right opportunity to develop their knowledge, skills, abilities and other personality characteristics (KSAOs) to perform effectively as leaders on the global stage. There were various approaches in developing competencies for global leaders. Much emphasis was given to experience-based and action learning such as international assignments, working with multicultural teams and first hand global leadership experience. Based on the findings, recommendations are made for developing effective global leadership.

Keywords: Developing global leadership, Effective global leadership, Global Leadership, Global leadership in Malaysia, Global leaders

\section{Introduction}

Malaysia aims to be a fully developed nation by 2020. This is the national vision. To achieve this, one of its major initiatives being formulated is the introduction of the New Economic Model (National Economic Advisory Council, 2010). Basically, the model is introduced to transform the nation from a middle-income nation to a higher income country. This model requires the country to move from factor-driven economy with efficiency driven economy and finally to innovationdriven economy.

But transforming the nation to higher income economy will require a new generation of leaders to lead organizations. These leaders must be competent enough to lead in diverse and complex environment.

"A recent survey of chief human resource officers (CHROs) found developing future leaders to be the most critical deliverable of the HR function to help their organization compete globally" (Caligiuri, 2013:177). Caligiuri (2013) argued that "the organizations better able to develop and deploy culturally agile leaders will gain competitive advantages in the future" (Caligiuri, 2013: 175).

But looking to the future we need new leadership ideas. Most often mentioned is the idea of global leadership (Ducker, 2012; Mendenhall et.al., 2001; Harris, Moran, \& Moran, 2004; Caligiuri, 2006; Ket de Vries, 2005; Abu Daud 
Silong et al. 2008; Rhinesmith, 1996; Brake, 1997; Abu Daud Silong et al. 2010). However, global leadership is a new phenomenon and not much empirical research has been conducted on the topic (Ducker, 2012). ".... Global leadership remains a nascent field, and there is much that still remains to be understood about global leadership processes. Importantly, the field continues to lack a specific, rigorous and widely accepted definition of the construct" (Mendenhall et al., 2012: 493).

The term global leadership only appeared in the literature towards the end of the 20th century. ".... Formal conceptual definitions are a necessary condition to enable robust theory-building and empirical research. Without clear and commonly accepted definitions, there is a risk that the research domain becomes increasingly fragmented and lose their ability to develop a common body of knowledge and make sense of potentially conclusive empirical results." (Mendenhall et al., 2012: 493)

"A rigorous, precise and commonly accepted definition is a necessary condition for an academic domain, especially in a nascent field such as global leadership, to advance conceptually and empirically" (Mendenhall et al., 2012: 501). Therefore, this paper will try to answer the questions: (1) what is global leadership? (2) How do you develop global leadership?

\section{Literature Review}

This section provides the key concepts related to the topic of developing effective global leadership. It includes topics on: global leadership, definitions of global leadership, effective global leadership, developing effective global leadership.

\subsection{Global leadership}

Global leadership is a key human resource issue in leadership development, but existing knowledge is limited. Globalization continues to affect organizations at different levels. These calls for a corresponding shift in global leadership paradigms. Strategic leaders in organizations require a more diverse repertoire of attributes to effectively confront emerging global challenges such as free flow of capital and labor, changing technologies and cultural dynamics. A diverse environment provides opportunity about critical understanding of differences and improve the corporate cultures (Popescu, 2013).

Globalization has increased complexity and ambiguity in organizations. Global leaders need to develop their skills, knowledge and abilities about leading in a multicultural environment with different groups.

\subsection{Definitions of Global Leadership}

Global leadership is a recent phenomenon. It began to appear in the literature in early 1990s. The earliest publish literature on global leadership was in 2001 (Ducker, 2012). Basically "Global leadership is relatively a new concept, a fact that is testified by the lack of an established definition, a paucity of field research and limited methodological sophistication" (Ducker, 2012:1). It is very much a debatable term and little agreement what global leaders do and what qualities they possess. As a field of study it is one in its "nascence".

There are many definitions of global leadership, for examples:

Global leaders are individuals who effect significant positive change in organizations by building communities through the development of trust and arrangement of organizational structures and processes in context involving multiple cross-boundary stakeholders, multiple sources of external cross-boundary authority, and multiple cultures under conditions of temporal, geographical and culture complexity (Mendenhall et al. 2008: 17).

"Global leader is required to reality adapt to change and deal with the complexity of interpersonal relationship in order to flourish in an environment of ambiguity comprised of cultural differences in values, beliefs, attitudes, and behaviors" (Tuleja, 2014: 5).

Referring to Table 1, Mendenhall et al. (2012) mentioned that various definitions of global leadership were given (Mendenhall et al. 2012), Global leadership has also been defined as leaders who are "capable of operating effectively in a global environment while being respectful of cultural diversity" (Harris, Moran, \& Moran, 2004: 25).

Another definition was introduced by Caligiuri (2006), where she defined global leaders as who are in a job with some international scope (Spreitzer, McCall, \& Mahoney, 1997) and must effectively manage through are complex, changing, and often ambiguous global environment (Bartlett \& Choshal, 1992; McCall, Lomboardo, and Morrison, 1998). 
After reviewing the literature there were many definitions of global leadership found. Based on the search, various definitions from 1997 until 2014 were described and discussed by many authors. As mentioned by Mendenhall et al. (2012), from the discussions global leadership can be interpreted in various ways (Table 1):

It means diversity - diverse employees/system and operation (Ding, 2013): multiple cross-boundary, stakeholders and multiple cultures (Mendenhall et. Al., 2008): geography and culture (Conger et al., 2012): culture, gender, religion or social class (Hope, 2007): diverse groups and system (Beechler \& Javidan, 2007): cultural diversity (Harris et al., 2004), diverse countries, cultures and customers (Gregersen et.al., 1998). It means complexity - uncertainty, ambiguity and complexity (Hope, 2007): manage complexity (Caligiuri, 2006)

It means working on the global stage - ability to work on the global stage (Caligiuri and Tarique, 2009): international job scope (Caligiuri, 2006): global responsibilities (Suutari, 2002): global position such as global executive (McCall and Hollenbeck, 2002): job with international scope (Spreitzer et al., 1997), global competition and world-class performance (Brake, 1997).

It means flexibility - change ways to one situation or country to another (Jvidan, 2006). It means global mindset work together towards a common vision and common goal for the global community (Osland \& Brid, 2005): formulate and implement strategies that enhance global reputation and produce competitive advantage (Petrick, et al., 1999): able to articulate a globally encompassing vision and to communicate that vision to people around the world (Adler, 1997).

It means networking - to work together to achieve individual, organizational, and societal goals (Adler, 1997)

Based on the discussion, global leadership can be defined as a leader who operates on a global stage with the global mindset in an environment that is complex and diverse with competencies that includes networking and flexibility.

Table 1: Definition of Global Leadership

\begin{tabular}{|c|c|}
\hline Author & Definition \\
\hline Maryam Hassanzadeh (2014) & $\begin{array}{l}\text {....global leadership can be defined as a leader who operates on a global stage with the global } \\
\text { mindset in an environment that is complex and diverse with competencies such as networking and } \\
\text { flexibility. }\end{array}$ \\
\hline Freshwater (2014) & $\begin{array}{l}\text {....Global leaders recognize the aspirational, innovative and creative perspectives that have both } \\
\text { driven the agenda to date, these being the legacy issues, and the drive towards transforming and } \\
\text { building on those successes to date. And, importantly are able to hold them in creative tension. }\end{array}$ \\
\hline Ding, H.(2013) & $\begin{array}{l}\text {....Global leaders who have unique skills to lead diverse employees and understand different } \\
\text { countries' legal systems and business operation. }\end{array}$ \\
\hline Conger, J. A \& O'Neill, C. (2012: 53) & $\begin{array}{l}\text { Basically, the term refers to an organization's leadership talent who work across geographic and } \\
\text { cultural boundaries. }\end{array}$ \\
\hline Prewitt et al. (2011:16) & $\begin{array}{l}\text {... global leadership capability is behaviorally based and is a mixture of varied cultural competencies as } \\
\text { well as leadership skills. (Carey, et al.) }\end{array}$ \\
\hline Youssef \& Luthans (2010: 541) & $\begin{array}{l}\text { Positive global leadership as "the systematic and integrated manifestation of leadership traits, } \\
\text { processes, intentional behaviors, and performance outcomes that are elevating, exceptional and } \\
\text { affirmatory of the strengths, capabilities and developmental potential of leaders, their followers and } \\
\text { their organizations over time and cross culture." }\end{array}$ \\
\hline Cohen (2010: 3) & $\begin{array}{l}\text { A leader who will not only have to be generally effective in traditional skills expected but also with } \\
\text { additional knowledge, skills and above all mindset to navigate through the complexities brought on by } \\
\text { moving beyond traditional border. }\end{array}$ \\
\hline Caligiuri \& Tarique (2009: 336) & $\begin{array}{l}\text { Global Leader [are] high level professional such as executives, vice presidents, directors, and } \\
\text { managers who are in jobs with some global leadership activities such as global integration } \\
\text { responsibilities. Global leaders play an important role in developing and sustaining a competitive } \\
\text { advantage. }\end{array}$ \\
\hline $\begin{array}{l}\text { Mendenhall, Osland, Brid, Oddou \& } \\
\text { Maznevski, (2008: 17) }\end{array}$ & $\begin{array}{l}\text { Global Leaders are individuals who effect significant positive change in organizations by building } \\
\text { communities through the development of trust and the arrangement of organizational structures and } \\
\text { process in context involving multiple cross-boundary stakeholders, multiple sources of external cross- } \\
\text { boundary authority, and multiple cultures under conditions of temporal, geographical and cultural } \\
\text { complexity. }\end{array}$ \\
\hline Osland (2008: 34) & Anyone who leads global change efforts in public, private, or non-profit sectors is a global leader. \\
\hline Beechler \& Javidan (2007: 140) & $\begin{array}{l}\text { Global leadership is the process of influencing individuals, groups, and organizations (inside and } \\
\text { outside the boundaries of the global organization) representing diverse cultural/political/institutional } \\
\text { systems to contribute towards the achievement of global organization's goals. }\end{array}$ \\
\hline Hope (2007) & $\begin{array}{l}\text { Tomorrow's global leaders will encounter an environment that is constantly changing. Replete with } \\
\text { uncertainty and ambiguity, and increasingly complex - with greater cultural diversity and technological } \\
\text { advancement. }\end{array}$ \\
\hline Hope (2007) & $\begin{array}{l}\text { Global leaders need to think beyond their own organizations and predetermined categories of culture, } \\
\text { gender, religion, or social class and be able to continuously transform themselves and others. }\end{array}$ \\
\hline Javidan (2006) & al leader be able to quickly change his/her ways from one situation or country to another. \\
\hline
\end{tabular}




\begin{tabular}{|c|c|}
\hline Caligiuri (2006: 219) & $\begin{array}{l}\text { Global leaders, defined as executives who are in jobs with some international scope, must effectively } \\
\text { manage through the complex, changing, and often ambiguous global environment. }\end{array}$ \\
\hline Caligiuri (2006:219) & $\begin{array}{l}\text { Global leaders expand business into foreign markets, conceive strategies on a global basis, manage } \\
\text { and motivate geographically dispersed and diverse teams and the like (Bartleett \& Ghoshal, 1992; } \\
\text { MccALL, Lombardo, \& Morrison, 1998). }\end{array}$ \\
\hline Oslan \& Brid (2005: 123) & $\begin{array}{l}\text { Global leadership is the process of influencing the thinking, attitudes, and behaviors of a global } \\
\text { community to work together synergistically toward a common vision and common goal. }\end{array}$ \\
\hline Harris, Moran, \& Moran (2004: 25) & $\begin{array}{l}\text { Global leader are capable of operating effectively in global environment while being respectful of } \\
\text { cultural diversity. }\end{array}$ \\
\hline Terrell \& Rosenbusch (2013:41-42) & $\begin{array}{l}\text {....there is not just one type of global leader, the term "global leader" was defined as someone "who } \\
\text { do[es] global work"(McCall \& Hollenbeck, 2002, p. 32), meaning his or her normal, day-to-day work } \\
\text { responsibilities involved leading other organizational members in multiple countries, time zones, } \\
\text { languages, national cultures or organization cultures. }\end{array}$ \\
\hline Suutari (2002:229) & Global leaders are managers with global integration responsibilities in global organizations. \\
\hline McCall \& Hollenbeck (2002:32) & $\begin{array}{l}\text { Simply put, global executives are those who do global work. With so many kinds of global work, again } \\
\text { depending on the mix of business and cultural crossings involved, there is clearly no one type of global } \\
\text { executive. Executives, as well as positions, are more or less global depending upon the roles they } \\
\text { pay, their responsibilities, what they must get done, and the extent to which they cross borders. }\end{array}$ \\
\hline $\begin{array}{l}\text { Petrick, Scherer, Brodzinski, Ouinn \& } \\
\text { Ainina (1999: 58) }\end{array}$ & $\begin{array}{l}\text { Global strategic leadership [...] consists of the individual and collective competence in style and } \\
\text { substance to envision, formulate, and implement strategies that enhance global reputation and } \\
\text { produce competitive advantage. }\end{array}$ \\
\hline Gregersen, Morrison, \& Black (1998: 23) & Leaders who can guide organizations that span diverse countries, cultures, and customers. \\
\hline $\begin{array}{l}\text { Adler (1997); Bartlett, \& Ghoshal (1989); } \\
\text { Hamel \& Prahalad (1986) }\end{array}$ & $\begin{array}{l}\text { Global leaders, unlike their domestic counterparts, must be able to articulate a globally encompassing } \\
\text { vision and to communicate that vision to people around the world in ways that inspire them to work } \\
\text { together to achieve individual, organizational, and societal goals. }\end{array}$ \\
\hline Spreitzer, McCall, \& Mahoney (1997: 7) & $\begin{array}{l}\text { An executive who is in a job with some international scope, whether in an expatriate assignment or in } \\
\text { a job dealing with international issues more generally. }\end{array}$ \\
\hline Brake (1997: 38) & $\begin{array}{l}\text { Global leaders- at whatever level or location- will 1) embrace the challenges of global competition, 2) } \\
\text { generate personal and organizational energies to confront those challenges, and 3) transform the } \\
\text { organizational energy into world-class performance. }\end{array}$ \\
\hline
\end{tabular}

Adapted from Mendenhall et al. 2012

\subsection{Effective global leadership}

The ability of global leader to effectively operate within diverse culture is increased with awareness and adoption to the environment of host countries. To do this, global leaders need to motivate follower and it can access through the relationship and communication between global leader and workers and build trust through the sensitivity about their cultural empathy and context (Popescu, 2013, Pera, 2013).

Conger (2014) writes "... organization can make the costly mistake of selecting locally effective leaders for global leadership positions-without appropriately assessing their ability to lead in global contexts. Conversely, employees who may less effective leaders in a local context may possess the capabilities and skills to lead successfully in global environment" ( $p$ 203). He also highlighted "limit experiences" as another costly mistake to develop individual as effective global leader.

Leadership styles apply differently in each state. The effective global leader needs to be aware of host countries' leadership style. Calwell (2013) says" displaying western-style leadership behavior may create a strong global leadership brand for the young Asian leader, but he or she may not be trusted or respected locally. Thus, these Asian leaders often find themselves caught between the conflicting leadership demands of the local cultural context and the global organization" (p51).

\subsection{Developing effective global leadership}

With rapid globalization, there is recognition for more global leadership development. Currently there was a shortage of global leaders and this accepted by most organizations. "It was noted that organizations need to improve at developing global leaders" (Terrell, S., 2011: 101). It was also emphasized that:

The challenges of sourcing leadership talent are particularly salient in today's global economy. As your organization's operations expand across the world, they will demand a mobile pool of leadership talent. Yet our research suggests a surprising number of organizations are struggling with critical shortages of what we call global leaders. (Conger \& 
O’Neill, 2012: 53)

Caligiuri (2006) identified KSAOs (knowledge, skills, abilities, other personality characteristics) for employees based on job task, and giving to the right people (those with the requisite KSAOs) the right development opportunities that will make leader who can work effectively on the global stage with global task and activities.

In reviewing the literature (Table 2), there is an indication that there were various approaches in developing global leaders. Much emphasis was given to experience-based learning such as action learning, international assignments, and working with multicultural teams. ".... Global leaders (a) develop through first -hand global leadership experiences; (b) learn the importance of cultural sensitivity, relationships and networks and curiosity or desire to learn...." (Terrell \& Rosenbusch, 2013: 42). Learning from experiences is considered a critical and effective approach. Table 2 identified some of the approaches in developing global leadership.

Conger and O'Neill (2012) mentioned effective global leader must a have a wider variety of competencies to lead in global stage rather than domestic leader. Caligiuri identified three erroneous assumptions which she called them as the root of problem for current global leadership development.These three are included: (1) the assumption that can develop cross-cultural competencies to anyone, (2) the assumption that all international assignments can be developed, and (3) the assumption that all global organizations are supporting the development of cultural agility. Many organizations fail to integrate the concept of global leadership into their talent management practices (Paraschive, 2013).

Nonetheless needs to select a pivotal role for developing global leaders. When comes to competencies required for global leadership, researchers identified several competencies which some of these competencies are difficult to deploy in practices and also in some situations they have overlap with domestic leadership models (Conger, 2014).

\subsubsection{Barriers for developing global leadership.}

Caliguiri (2013) mentioned about three misunderstandings about global leadership which are: cannot develop any leader as global leader, not all global assignments are effective and not all organizations can support developing global leadership.

Meanwhile Conger (2014) explained the reason of organizations' interest to develop local leader rather than global leader. He organized these problems as "cost", "time" and "trust". He believes global leaders can cost three or more times more than normal employees' salary when they work in their own countries. Expatriates leader's learning, takes three or more months for them to understand the effect of culture, economics, history and believes on decisions. The last point he mentioned is about trust. He explained that people usually trust their home countries nation rather than neighboring countries or those far away.

Conger also explained why global leadership has little value in fact of the organization to develop this group of leaders. He summarized the reasons into the four elements which are a less value in "global mobility", avoid of "bypassed for promotions", manager "hoard" their high potential person and last not least willingness of the person as individual to face challenges in expatriation.

Based on the above discussion if we need to develop effective global leader we have to focus in the three areas: (1) a person who want to lead as global leader, (2) the skill required to lead in global stage, and (3) the organization as complex environment.

\subsubsection{Developing a person as global leader}

Cohen explained global leader as "a leader who will not only have to be generally effective in traditional skills expected but also with additional knowledge, skills and above all mindset to navigate through the complexities brought on by moving beyond traditional border" (Cohen, 2010: 3 ).

In dynamic cross-cultural competencies and global leadership effectiveness study, Caligiuri and Tarique (2012) highlighted three personality characteristics for global leader which are openness to experience, extraversion, and neuroticism. However Conger (2014) believes there is no "universal personality" recognized for global leader albeit certain personalities may help global leader to be successful.

\subsubsection{Developing skills required to lead in a global stage}

Hui (2013) mentioned global leaders should have unique skills in leading diverse employees and also understand the 
legal systems and business operation of various countries. "Well-chosen job assignments are the most effective vehicle for developing global leadership talent. Formal assignments are not the primary for identifying global leadership talent" (Popescu, 2013:171)

\subsubsection{Developing organization as complex environment}

Before explaining how can develop an organization as global platform needs to understand the meaning of complexity. Based on the research done by Mendenhall et al. 2012 complexity includes:

(a) Multiplicity, which is referred to numbers and differences. It is about how to work with different people and also how to deal with various work roles (e.g. Numerous models of organizing, competing and governing).

(b) Interdependence, which refers to interconnection. In global age technology linked organizations and even nations easily and faster. "Interdependence is not the only feature of the external environment; it also is something companies create themselves to cope with the challenges of the external environment" (Lane et al., 2006:15).

(c) An ambiguity, which refers to the lack of information clarity, nonlinear relationships, and equivocality. Ambiguity "involves not being able to understand and interpret the data in a way that effectively guides action. The ambiguity goes beyond uncertainty" (Lane et al., 2006: 18).

(d) Flux, refers to the changing situations. "The whole system [of the global context] has been always in motion, always changing. And it seems to be changing at a faster rate all time" (Lane et al., 2006: 24)

There are various approaches to developing global leadership. Those approaches were summarized in Table 2.

Table 2: Approaches to Global Leadership Development

\begin{tabular}{|c|c|c|c|c|c|c|c|c|}
\hline & Conner & Dotlich & Gregersen & Lobel & Marquardt & Mendenhall & Osland & Suutar \\
\hline 360 feedback for personnel development & & & & & & $\mathrm{x}$ & $\mathrm{x}$ & \\
\hline action learning & & $\mathrm{x}$ & $\mathrm{x}$ & & $\mathrm{x}$ & $x$ & $\mathrm{x}$ & $\mathrm{X}$ \\
\hline Assessment & & & & & & $x$ & $\mathrm{x}$ & \\
\hline Coaching & & & & & & $\mathrm{x}$ & $\mathrm{x}$ & \\
\hline Cross-cultural experience & & & & & & $\mathrm{x}$ & $x$ & \\
\hline Education and feedback & $\mathrm{x}$ & & & & & & & \\
\hline Executive staffing & $x$ & & & & & & & \\
\hline Global assignment & & & & & & $\mathrm{x}$ & $\mathrm{x}$ & $\mathrm{x}$ \\
\hline High potential program & $x$ & & & & & & & \\
\hline Incentives for global performance & & & & & & $\mathrm{x}$ & $\mathrm{x}$ & \\
\hline International teams & & & & & & $\mathrm{x}$ & $\mathrm{x}$ & $X$ \\
\hline International training & & & & & & $\mathrm{x}$ & $\mathrm{x}$ & $\mathrm{x}$ \\
\hline International meeting & & & & & & $\mathrm{x}$ & $\mathrm{x}$ & $\mathrm{x}$ \\
\hline International travel & & & & & & $\mathrm{x}$ & $\mathrm{x}$ & $\mathrm{x}$ \\
\hline Line management ownership & $x$ & & & & & & & \\
\hline Overseas assignment & & & & & & $x$ & $\mathrm{x}$ & $\mathrm{x}$ \\
\hline Rewards & & & & & & $x$ & $x$ & \\
\hline Succession planning & $x$ & & & & & & & \\
\hline Tracking process & & & $\mathrm{x}$ & & & & & \\
\hline Training & & & $x$ & $\mathrm{x}$ & & $\mathrm{x}$ & $x$ & \\
\hline
\end{tabular}

Source: Terrell, S. (2011: 103)

\section{Methodology}

This section discussed the selection of research site and the participants, the case study using in-depth interview, collection of data and analysis of data.

\subsection{Selection of site and participants}

This study utilizes the qualitative approach. In qualitative study it is very important to make decisions regarding where to 
conduct the research and who to include as participants. Universiti Putra Malaysia is chosen as the site of the study because it is one of the premier universities in the country and also it is awarded one of the five research universities (RUs) in Malaysia. And more important, the researcher receives strong support and cooperation of the various parties of UPM. Further the researcher is a student of UPM and therefore quite familiar with the university structure and organization.

The selection of the participants was based on the purposive sampling procedures. The sampling included eight top past and present leaders of Universiti Putra Malaysia. They include those holding the post of Vice Chancellors and Deputy Vice Chancellors.

\subsection{In-depth interview}

This research employed qualitative methodology through the in-depth interview. These interviews were conducted with eight past and present top leaders of UPM. The participants were contacted for their agreements to be involved in the research. The date, time and place of the interview were decided after discussions with the participants. They were conducted at the residence, hotel, and office. The interviews lasted about one to two hours and they were recorded with their permissions. The interviews were conducted using an interview guide that has been pilot tested by the researcher.

For this research qualitative study was utilized to explore the phenomena of global leadership. It has been employed in many leadership studies using the interview, observation and document analysis techniques. Thus qualitative study is a very appropriate research design because it will elicit real experiences in the process of leading among the top leaders in UPM. It is a very useful technique in exploring real life situations. Thus the researcher will be able to understand the participants' leadership experiences in their own contexts. Through the in-depth interviews a qualitative researcher is able to understand and interpret the unique experiences of the participants.

In qualitative research, the researchers is the research instrument. For the researcher to be able to conduct this research she was exposed to the qualitative methodology. Thus she enrolled in basic and advance qualitative class conducted by the department. Also, she is involved in the Putra Leadership Development Project that used qualitative methodology through in-depth interviews. Thus she has the necessary skills to conduct qualitative research.

Being involved in this study, the researcher can interact with participants and the context of the research. Thus, it is a flexible technique that allows the researcher to continuously improve and refine the process appropriate to the context in new findings as the research progresses. Qualitative study provides the opportunity for the participants tell their stories based on their own experiences and in this research it focuses on their leadership experiences.

\subsection{Pilot study}

In qualitative research the data collection process can be refined through the pilot study. In this research, pilot study was used to improve the interview protocol and also to learn the research process of interviewing and to improve weaknesses before starting actual research. The researcher develops the protocol for the interview based on the review literature and also discussion with some academicians. Based on the result of the discussions the protocol for the in-depth interviews was developed.

Pilot study was employed to test the protocol for the in-depth interview. The researcher selected two participants for the pilot study. The first participant was an experienced practitioner who had work for many years with various multinational companies. The second participant was an academician who had experience in leadership positions at UPM. In this pilot study the researcher used the same procedure as the actual study. The main purpose of the pilot study was for the researcher to learn how to establish rapport, to integrate with the surroundings and to prepare the interview protocol. Based on the pilot study the researcher learned skills such as taking field notes, the process of interviewing and transcribing the responses. She also learned things such as the conduct of the interview, the time taken to complete the interview and the questions that were not clear to the participants. Based on the pilot study the researcher made several modifications to develop the final protocol for the in-depth interviews.

\subsection{Analysis of data}

Data were analyzed manually. The findings were categorized into themes and sub-themes. Data analysis was carried out simultaneously with the data collection phase. Interviews were transcribed verbatim, including pauses, laughs, and other remarks. The analysis was started as soon as transcribing was completed. The categories and themes were linked to 
each other so as to build a logical chain of evidence. This linkage enables the researcher to capture the general patterns and themes for further discussion and interpretation of the findings.

Data analysis was conducted in three phases:

1. Data reduction - the process of managing the files, transcribing the interview verbatim and reading over and over to be very familiar with data.

2. Data presentation - the process of establishing the links between the various codes and themes and also facilitating the process of report writing.

3. Verification of the data collected - the process of data reduction and presentation is to ensure the reliability and validity of what has been reported and interpreted that represented the real phenomenon that was being studied.

During the analysis process the researcher used the field notes as well as the data collected from interviews. The researcher used various categories to describe effective global leadership. The researcher read the transcriptions over and over again to observe the patterns of effective leadership that were repeated. Patton (1990) termed this technique as comparative pattern analysis.

\section{Findings and Discussion}

Based on the analysis three major themes are identified that includes ability, skill and knowledge and also various categories for each of the themes. Under the theme of ability, four categories are included such as willingness and being innovative, positive and open mindset. Whereas the theme skill include categories such as experience, collaboration, practice, technology savvy, linkage and networking and team working. Finally under the theme knowledge categories of cultural awareness and problem awareness were identified. Cultural awareness includes sub-categories of multicultural awareness and self-awareness (Table 3).

Table 3: Findings of the study

\begin{tabular}{|l|l|l|}
\hline Ability & Skill & Knowledge \\
\hline Willingness & Experience & $\begin{array}{c}\text { Cultural Awareness } \\
\bullet \quad \text { Multicultural awareness } \\
\text { Self awareness }\end{array}$ \\
\hline Innovative & Collaboration & Problem awareness \\
\hline Positive & Practice & \\
\hline $\begin{array}{c}\text { Global mindset } \\
\text { Open mind } \\
\text { Look beyond }\end{array}$ & Technology savvy & \\
\hline & Linkage and networking & \\
\hline & Team working & \\
\hline
\end{tabular}

\subsection{Ability}

Based on the findings of this study, the researcher concluded that we cannot develop any leader as a global leader. This was also supported by Caliguiri (2013) is his argument in developing global leadership. Not everyone can be a leader in certain fields or certain areas. Some people can be successful and effective at home, but as soon as they are out of their countries, they can only perform as a "village champion". They do not know how to handle diversity which is critical for global leaders. To be effective at the global stage, they require some abilities such as willingness, being innovative, positive and open mindset.

Among the above findings open mindset ranked higher that others in terms of its importance. Global leadership is about dealing with diversity. Thus appreciating differences is a key element in working effectively at the global stage. Going from local to global stage need a strategy, plan and thinking both at the global and local levels. McCall and Hollenbeck (2002:137) mentioned that " local leaders need to see the big picture beyond the local picture". Global leaders must never have certain set of ideas about "things" from the beginning. They must always have an open mind. By having an open mindset they will not get shocked by meeting new people. Leaders need to be open-minded, think globally in order to understand differences in people, and also differences in the environments where they come from. People with open-mindset can accept their mistakes and when they are aware of their faults, it is easier for them to find 
the solutions.

To be effective global leader, there is a need of willingness to work with global challenges. Global leaders when compared to the domestic leaders face different challenges. The challenges such as living far from their families and challenges of facing complex and uncertain environment. To overcome that situation, they must be positive and see all challenges as opportunities. And also they should not see all people as the same.

Positive global leaders need to be idealistic and have a world view as well. Global leaders need to be innovative. Parrey (2014) said they must develop more creativity and the ability to build a culture of innovation. Global leaders must have enough creativity and intelligence to make full use of a certain amount of money that they have and to "sell their idea" to bring money to their organizations.

\subsection{Skill}

Global leadership is different from domestic leadership. To be effective, global leaders need to have skills required to lead in globalization. Among the skills, experience ranked highest, while linkage and networking ranked next after the experience. Conger (2014:198) said that "a global leadership assignment can literally demand a transformation in how individuals see themselves. The term culture shock is often used to describe the power of experience". To develop global leaders, long life experiences have the same level of importance with work experiences. Overseas study will enhance the global leaders' experience about cultural differences. On the other hand, having international assignments like attending conferences, celebrations and mobility will also enhance the global skills required for global leaders.

The second important skills are linkage and networking. Networking is very important. Global leaders must meet people, entertain people, get people to know themselves. While they were into networking they also have to keep the linkages. Linkages and networking help global leaders to analyze each others strategies and plans. Thus, they can make a shortcut from their colleagues' success by collaborating with them.

Beside those skills mentioned above, global leaders should also have technology skills. This does not mean global leaders should be a programmer or IT experts, it just means that they have to be aware of rapid changes in technology and how technology can affect their businesses. As long as global leaders deal with groups of people, they must know how to work as a group with their staff. People in organizations need to feel comfortable to share their problems. Otherwise, their problems will remain unsolved. To accomplish that they need to trust their leaders and global leaders can build that trust through engaging in effective communication.

\subsection{Knowledge}

To develop global leaders, organizations should pay vital attention to their talents. Global assignments enhance global leaders information about different cultures. First global leaders should be aware about their own culture. Where they come from? What are their norms? Who are their heroes? And then they need to be aware of the host country's culture as well. It may get months to learn the new cultures, but it is vital for global leaders. Host countries Human Resource Manager is responsible to provide the expatriate leaders' knowledge (Conger, 2014). Globalization is involved with complexity and uncertainty, it requires global leaders' awareness about uncertaint problems to make quick decisions.

\section{Conclusion}

In developing global leaders, organizations should select the right people who are able and interested to work outside of their own countries. "One of the most useful criteria is the degree to which an individual is motivated to work outside their countries" (Conger, 2014:201). Choosing effective local leaders and training them to be global leaders without paying attention to their ability out of their own country can be a costly mistake for organizations.

The successful global leaders have a unique set of skills such as adaptation to the new culture, networking and linkages. As what Caliguiri (2013) mentioned, not all global assignments can be effective to develop global leaders. Selecting the required assignments for certain field is key element to enhance global leaders' knowledge. In the end, putting the knowledge into the practice will produce effective global leader.

Based on the literature, findings and discussion, we can conclude that:

a) Global leadership can be defined as a leader who operates on a global stage with the open mindset in an environment that is complex and diverse. When leading in global stage they are required to have with certain competencies such as networking and flexibility. 
b) To develop a global leader we need to look at the right person who wants to lead at the global stage. Further, we have to give them the right skills and knowledge and also opportunities to develop themselves. Also the organization must provide the necessary environment to work as a global leader.

We recommend that a systematic global leadership development program must be designed to develop global leaders. It should focus on providing experiential based-learning that provide international exposure and understanding.

\section{References}

Abu Daud Silong, Ismi Arif Ismail, Zaharah Hassan and Soaib Asmiran. (2010). Global leadership for World Class University. Research Report submitted to the Ministry of Higher Education. Serdang: Universiti Putra Malaysia.

Abu Daud Silong, Madinah Mohamad, Zaharah Hassan \& Ismi Ariff. (2008). Changing roles and competencies for effective public sector leadership. Jurnal Pengurusan Awam, 7(1): 27-46

Brake, T. (1997). The global leader, critical factors for creating the world class organization. Chicago, Illinois: Irwin Professional Publishing.

Caligiuri, P. (2013). Developing culturally agile global business leaders. Organizational Dynamics, 42(2013) 175-182.

Caligiuri, P. (2006). Developing global leaders. Human Resource Management Review, 16: 219-228.

Caligiuri, P., Tarique, I. (2012). Dynamic cross-cultural competencies and global leadership effectiveness. Journal of World Business, 47(2012) 612-622.

Christie, C. (2012). Tomorrow's global leaders. People \& Strategy, 36 (3), 49-53.

Cohen, S. L., (2010). Effective global leadership requires a global mindset. Industrial and Commercial Training, 42 (1), 3-10.

Conger, Jay A. (2014). Addressing the organizational barriers to developing global leadership talent. Organizational Dynamic 43, 198204.

Conger, J. A., and O'Neill, C. (2012). "Building the Bench for Global Leadership", HR People and strategy 35(2):53-57.

Ding, Hui (2013). Virtual global leadership model: exploratory research of leadership. Proceedings of $7^{\text {th }}$ Global Business and Social Science Research Conference. Radisson blu hotel, Beijing, China

Ducker, C. (2012). Global leadership - grasping a slippery term. Encounters Mission Journal, 39: 1-9.

Harris, P. R., Moran, R. T., \& Moran, S. V. (2004). Managing cultural differences - global leadership strategies for the $21{ }^{\text {st }}$ century (6 $6^{\text {th }}$ Ed). Oxford: Butterworth-Heinemann/Elsevier.

Ket de Varies, M. F. (2005). Global executive leadership inventory. San Francisco: John Wiley and Sons.

Lane, H. W., Maznevski, M. L., \& Mendenhall, M. E. (2006). Globalization: Hercules meets Buddha. In G. Scholz (Ed.), Global talent: An anthology of human capital strategies for today's borderless enterprise (pp. 3-32). Washington, DC: Human Capital Institute.

Mendenhall, M. E., Reiche, B. S., Bird, A. and Osland, J. (2012). Defining the "global" in global leadership, Journal of World Business, 47 (2012), 493-503.

Mendenhall, M. E., Osland, J. S., Bird, A., Oddou, G. R., \& Maznevski, M. L. (2008). Global leadership: Research, practice, and development. London and New York: Routledge.

Mendenhall, M. E., Kühlmann, T. M., \& Stahl, G. K. (2001). Developing global business leaders: Policies, processes, and innovations. London Greenwood Publishing Group

McCall, M. W., Jr., \& Hollenbeck, G. P. (2002). Developing global executives. Boston, MA: Harvard Business School Press.

National Economic Advisory Council. (2010). New Economic Model for Malaysia, Part 1. Putajaya: Percetakan Nasional Malaysia Berhad.

Paraschive, Gavril (2013). "Gendered Decision-making Practices in the Juvenile Justice System," Geopoliticals, History, and International Relations 5(2): 118-123.

Parrey, D. (2014). The global leadership competencies we are not teaching. Chief Learning Officer, P (52-55).

Patton, M. Q. (1990). Qualitative evaluation and research methods (2nd ed.). Newbury Park, CA: Sage Publication.

Pera, Aurel (2013), "The Social Aspects of Technology-enhanced Learning Situations," Geopolitics, History, and International Relations $5(2):$ :118-123.

Popescu, G. H., (2013). Macroeconomics, effective leadership, and global business environment. Contemporary Reading in Law and Social Justice, 5(2), 2013, pp 170-176.

Rhinesmith, S. H. (1996), A manager's guide to globalization: Six skills for success in a changing world (2nd Ed.), New York, NY: The Mc Graw-Hill.

Terrell, S. (2011). How global leader develop: A phenomenplogical study of global leadership development. The Graduate School of Education and Human Development of The Geore Washington Univrsity.

Terrell, S. and Rosenbusch, K. (2013). Global leadership development: What global organization can do to reduce leadership risk, increase speed to competence, and build global leadership muscle. People \& Strategy, 36(1), 41-46.

Thomas, R., Bellin, J., Jules, C. and Lynton, N., (2013). Developing tomorrow's global leaders. MIT Sloan Management Review, Fall 2013 10-11.

Tuleja, Elizabeth A, (2014). Developing cultural intelligence for global leadership through mindfulness. Journal of Teaching in International Business, 25: 5-24, 2014. 